\title{
EVALUASI USER INTERFACE APLIKASI GOJEK TERHADAP PENGGUNA APLIKASI DI KOTA AMBON DENGAN METODE HEURISTIC
}

\author{
TRIENTJE MARLEIN TAMTELAHITU1, NUSYE MOZES Y LEWAHARILLA², JOANNA CRISTY PATTY3,* \\ Universitas Kristen Indonesia Maluku1,2,3 \\ trienmarlein77@gmail.com ${ }^{1}$ \\ cristyjoanna18@gmail.com*
}

\begin{abstract}
At this time the online motorcycle taxi application in Indonesia has grown and is experiencing rapid growth. This can be seen from the many online motorcycle taxi applications that have started providing services and information through an application, especially with a mobile application. Through this development, we can benefit from user involvement in using a good online motorcycle taxi application. Usability and credibility are believed to be one of the factors that influence the involvement of this development and growth. One of the ojegs based on mobile application technology used by the public is Go-Jek. Therefore, this paper presents an empirical study in evaluating the usability of the Go-jek mobile application. Software testing needs to be done so that it can be seen whether the software being developed meets the needs of end users. The results obtained show that knowing the severity of the application can be used to improve the Go-jek application.
\end{abstract}

Key Words : Ambon, Mobile Application, Go-jek, Heuristic, Severity

\begin{abstract}
ABSTRAK
Pada saat ini aplikasi ojek online di Indonesia telah berkembang dan mengalami pertumbungan yang pesat. Itu terlihat dari banyaknya aplikasi ojek online yang sudah mulai memberikan layanan dan informasi melalui sebuah aplikasi terutama dengan aplikasi mobile. Melalui perkembangan ini kita dapat mengambil manfaat dari keterlibatan pengguna dalam menggunakan aplikasi ojek online yang baik, tentang kegunaan dan kredibilitas diyakini menjadi salah satu factor yang mempengaruhi keterlibatan perkembangan dan pertumbuhan itu. Salah satu ojek berbasis teknologi aplikasi ponsel yang digunakan oleh masyarakat adalah Go-Jek. Oleh karena itu, Makalah ini menyajikan studi empiris dalam mengevaluasi usability aplikasi mobile Go-jek. Pengujian perangkat lunak perlu dilakukan agar dapat diketahui apakah perangkat lunak yang dikembangkan telah memenuhi kebutuhan pengguna akhir. Hasil yang diperoleh menunjukan bahwa dengan mengetahui severity dari aplikasi tersebut, dapat digunakan untuk perbaikan pada aplikasi Go-jek.
\end{abstract}

Kata Kunci: Ambon, Aplikasi Mobile, Go-jek, Heuristic, Severity 


\section{PENDAHULUAN}

Salah satu ojek berbasis teknologi aplikasi ponsel yang saat ini digunakan oleh masyarakat adalah Go-Jek. Salah satu pendiri Go-Jek adalah Nadiem Makarim [1].

Pada awal berdirinya, Go-jek hanya melayani pesanan ojek melalui telepon, namun pada bulan januari 2015, Go-jek telah berkembang dengan menghadirkan aplikasi ponsel yang dapat digunakan sebagai media pemesanan secara online [2]. Gojek dikenal sebagai ojek modern dan professional. Para driver telah dilengkapi dengan handphone berbasis android atau IOS dengan tujuan memudahkan driver dalam berhubungan dengan para user dan dapat dengan mudah memperoleh rute terbaik untuk melakukan pengantaran penumpang [3].

Riset yang dilakukan Lembaga Demografi Fakultas Ekonomi dan Bisnis Universitas Indonesia (LD FEB UI), pada 2018 Gojek berhasil mencapai nilai transaksi hingga Rp 44,2 triliun, naik tiga kali lipat dari tahun sebelumnya [4], aplikasi Go-jek telah banyak digunakan oleh pengguna tetapi belum tentu cocok untuk pengguna yang lain.

Oleh karena itu, pengujian perangkat lunak perlu dilakukan agar dapat diketahui apakah perangkat lunak yang dikembangkan telah memenuhi kebutuhan pengguna akhir, telah sesuai dengan metode yang digunakan, serta mendokumentasikan hasil pengujian yang berisikan informasi yang berkaitan dengan perangkat lunak yang diuji dengan spesifikasi yang telah ditentukan.

\section{TINJAUAN PUSTAKA}

\section{Go-jek}

Go-jek adalah perusahaan penyedia jasa pemesanan ojek yang menggunakan teknologi aplikasi android. Aplikasi Go-Jek dapat diunduh melalui smarthphone baik android dan iOS [2][5]. Langkah pertama pada saat menggunakan layanan Go-Jek adalah melakukan pendaftaran/registrasi awal dengan memasukkan alamat email, nama, nomor telepon,dan password. Setelah pendaftaran/ registrasi berhasil, pengguna dapat memilih layanan yang tersedia di dalam aplikasi Go-Jek. Langkah selanjutnya, pengguna dapat memasukan alamat tempat asal dan alamat tempat tujuan. Kemudian aplikasi Go-Jek akan memberikan informasi mengenai keberadaa pengendara, prediksi waktu, identitas diri dari pengendara (nama, foto dan nomor telepon), dan harga. Setelah selesai proses penggunaan layanan, aplikasi Go-Jek akan memberikan kesempatan kepada pengguna untuk dapat memberikan penilaian atas pelayanan yang sudah diberikan oleh pengendara Go-Jek.

\section{Usability}

Usability adalah analisis yang menentukan seberapa mudah pengguna dalam menggunakan antarmuka suatu aplikasi [6-9]. Usability memiliki komponen majemuk dan biasanya berkaitan dengan lima atribut : Learnbility, Efficiency, Memorability, Error, Satisfaction. Jika sistem tidak mampu memenuhi harapan pengguna, maka pengguna akan lebih memilih beralih ke sistem lain [6]. Salah satu metode yang terkenal untuk mengukur tingkat usability adalah heuristic evaluation/evaluasi Heuristic [10].

\section{Heuristic Evaluation/Evaluasi Heuristic}

Heuristic Evauation/Evaluasi Heuristic adalah sebuah inspeksi interface/antamuka yang sistematik dengan cara mengamati sebuah interface/antarmuka dan menemukan hal baik dan hal buruk didalamnya, biasanya dilakukan oleh evaluator yang mampu menggunakan pedoman [10 -13]. Evaluator mengukur kegunaan, efisiensi, dan efektivitas antarmuka yang awalnya ditentukan oleh Jakob Nielsen pada tahun 1994 [11]. Usability Heuristics yang terus berkembang sebagai tanggapan terhadap penelitian pengguna dan perangkat baru, meliputi :

1. Menentukan pengguna(evaluator) yang akan mengevaluasi aplikasi.

Peneliti menentukan evaluator / koresponden yang akan menguji usability aplikasi yang ada. Dapat dilakukan dengan mengambil acak koresponden yang ada dalam satu lingkungan.

2. Mengidentifikasi masalah usability dengan menerapkan langkah pada metode heuristic :

a. Visibility of System Status:

Sebuah sistem akan selalu memberikan informasi kepada pengguna mengenai apa yang terjadi pada sistem. Pengguna langsung mengetahui informasi yang tersedia pada tampilan aplikasi. Menu yang ditampilkan sudah sesuai dengan isinya.

b. Match between system and the real world:

Sistem harus "berbicara" sesuai dengan yang biasanya digunakan oleh pengguna. Misalkan tombol yang digunakan sudah sesuai dengan fungsinya. Menyediakan lebih dari satu bahasa untuk memenuhi kebutuhan pengguna.

c. User Control and Freedom:

Menyediakan pilihan solusi ketika pengguna melakukan sesuatu dan hasilnya error. Misalkan tombol undo, 
redo dan back. Pengguna juga dapat melakukan aktivitas dengan Ieluasa sesuai kebutuhan.

d. Consistency and Standards:

Standar penulisan pada setiap menu harus konsisten,misalkan jenis dan ukuran huruf harus sama di setiap menunya. Pemahaman sebuah kata dan kalimat, situasi dan aksi harus mengikuti standar yang ada.

e. Error Prevention:

Aplikasi yang dibuat harus memiliki pesan error yang mudah dimengerti jika pengguna melakukan kesalahan input ketika melakukan aktivitas.

f. Recognition rather than recall: Instruksi dan informasi pada sistem harus mudah diakses dan jelas terlihat pada saat dibutuhkan, user tidak perlu mengingat informasi yang ada di setiap menu.

g. Flexibility and Efficiency of use: Aplikasi yang dibuat harus dapat mengakomodasi dari seluruh pengguna baik pengguna yang sudah ahli maupun pengguna umum sesuai dengan budaya, bahasa maupun fisik pengguna.

h. Aesthetic and minimalist design:

Aplikasi memberikan informasi yang relevan sehingga tidak mengurangi visibilitas dan usability.

i. Help users recognize, diagnose, and recover from errors:

Membantu pengguna untuk Mengenali, Mendiagnosa dan Mengatasi Masalah ketika melakukan aktivitas pada aplikasi.

J. Help and Documentation:

Aplikasi harus menyediakan fungsi "help" untuk pengguna dapat mempelajari aplikasi yang sedang digunakan.

\section{METODE}

Dalam penelitian ini metode heuristic neilsen telah diterapkan untuk memenuhi tujuan dari peneliti ini. Tahap awal penelitian dimulai dengan membuat kuisioner berdasarkan persyaratan penelitian. Dalam hal ini kuisioner diadaptasi dengan prinsip dasar dalam metode heuristic neilsen, kemudian disesuaikan dengan area kegunaan mobile [14].

\section{A. Kuisioner Usability}

Menggunakan kuisioner dapat memastikan bahwa pertanyaan yang di berikan kepada peserta sama dan tanggapan yang diperoleh di dapat dengan cepat. Setiap peserta diminta untuk menanggapi menggunakan lima poin skala likert, yang bisa dengan jelas menunjukan tingkat kesepakatan setiap peserta dengan pernyataan yang ada didalam kuisioner. Dalam skala linkert kita dapat membeda-bedakan argument pada setiap penelitian [15].

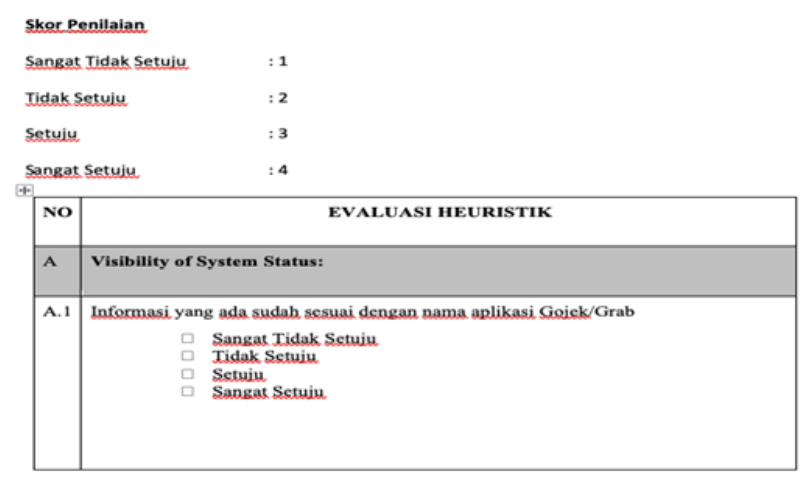

Gambar 1. Contoh Pertanyaan dalam Kuisioner

\section{B. Peserta}

Studi empiris ini dilakukan di Kota Ambon, Indonesia. Sebanyak 86 peserta merupakan mahasiswa dari 2 universitas di Kota Ambon dan pengambilan data dalam studi ini dilakukan peserta secara sukarela. Penelitian ini adalah penelitian eksplorasi menjelaskan jumlah peserta yang agak terbatas. Dalam penelitian ini peserta berasal dari 2 universitas di Kota Ambon yaitu Universitas Kristen Indonesia Maluku dan Universitas Pattimura, penjelasan yang jelas tentang tujuan penelitian ini diberikan kepada peserta sebelum proses dimulai.

\section{Prosedur Evaluasi}

Pada penelitian ini 86 peserta diberikan tugas untuk mencoba melakukan interaksi pada aplikasi mobile yang menjadi tujuan penelitian ini. Setiap evaluasi dilakukan dalam 3 fase yang sama yaitfu 1. Ulasan gratis; 2. Interaksi berbasis tugas; dan 3. Kuisioner. Ulasan gratis memungkinkan peserta melihat dan menggunakan aplikasi mobile atau hanya fokus pada elemen desain pada interface tertentu dalam aplikasi. Dengan ini peserta yang baru pertama kali menggunakan aplikasi ini memperoleh interaksi awal dan membentuk persepsi umum mereka dapat terbentuk.

Setelah itu, para peserta diminta untuk melakukan interaksi dengan mengikuti panduan yang telah ada pada kuisioner pada aplikasi mobile yang menjadi target penelitian. Untuk itu, lembar tugas yang disesuaikan dengan acuan 10 prinsip heuristic Nielsen diberikan kepada peserta. Para peserta diminta untuk melakukan tugas-tugas sesuai dengan kuisioner satu persatu tanpa batas waktu. Setelah menyelesaikan semua tugas, para peserta diminta untuk melakukan pengisian 


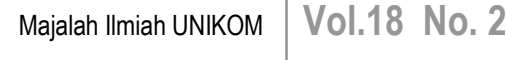

kuisioner evaluasi usability heuristic Nielsen.

\section{Analisis Data}

Untuk melakukan analisis persepsi pengguna tentang evaluasi kegunaan terhadap aplikasi gojek yang menjadi target, data kuisioner dan observasi di olah menggunakan skala linkert dengan satu poin untuk pertanyaan "sangat tidak setuju". Dua poin untuk pernyataan "tidak setuju", tiga poin untuk pernyataan "setuju" dan empat poin untuk pernyataan "sangat setuju". Langkah selanjutnya adalah menghitung setiap skor rata - rata untuk sepuluh elemen heuristic untuk setiap evaluasi dilakukan. Rating tingkat keparahan diberikan berdasarkan dengan hasil rata-rata. Tabel 1 menjunjukan klasifikasi severity rating yang telah di dapat dalam penelitian ini.

Tabel 1. Saverity Rating Classification

\begin{tabular}{|c|c|}
\hline \multicolumn{2}{|c|}{ Severity rating } \\
\hline $0 \%-19.99 \%$ & 4-catastrophe \\
\hline $20 \%-39.99 \%$ & 3-major problems \\
\hline $40 \%-59.99 \%$ & 2-minor problems \\
\hline $60 \%-79.99 \%$ & 1-cosmetic problems \\
\hline $80 \%-100 \%$ & 0-perfect \\
\hline
\end{tabular}

\section{HASIL DAN PEMBAHASAN}

\section{Data Penelitian}

Penelitian dilakukan dengan menggunakan Data Demografi yang terlampir di dalam kuisioner penelitian. Dengan Data Demografi yang terlampir berupa Jenis Kelamin, Usia, Lamanya Penggunaan Smartphone, Ukuran layar smartphone, Kegiatan yang dilakukan pada smartphone, Kegiatan dalam Penggunaan aplikasi Gojek, dan Seringnya pengaksesan aplikasi Gojek, berikut adalah Tabel data demografi.

Tabel 2. Jumlah Responden Unpatti berdasarkan Jenis Kelamin

\begin{tabular}{|c|c|c|}
\hline Jenis Kelamin & (orang) & $\begin{array}{c}\text { Jumlah } \\
\%\end{array}$ \\
\hline Laki - Laki & 13 & 26 \\
\hline Perempuan & 37 & 74 \\
\hline Jumlah & 50 & 100 \\
\hline
\end{tabular}

Trientje Marlein T, Nusye Mozes Y, Joanna Cristy P

Tabel .3 Jumlah Responden UKIM berdasarkan Jenis Kelamin

\begin{tabular}{|c|c|c|}
\hline Jenis Kelamin & (orang) & $\begin{array}{c}\text { Jumlah } \\
\%\end{array}$ \\
\hline Laki - Laki & 15 & 42 \\
\hline Perempuan & 21 & 58 \\
\hline Jumlah & 35 & 100 \\
\hline
\end{tabular}

Tabel 4. Jumlah Responden Unpatti

\begin{tabular}{|c|c|c|}
\hline $\begin{array}{c}\text { Umur } \\
\text { (tahun) }\end{array}$ & (orang) & $\begin{array}{c}\text { Jumlah } \\
\%\end{array}$ \\
\hline $16-20$ & 7 & 14 \\
\hline $21-30$ & 38 & 76 \\
\hline $31-37$ & 5 & 10 \\
\hline Jumlah & 50 & 100 \\
\hline
\end{tabular}

Tabel 5. Jumlah Responden UKIM

\begin{tabular}{|c|c|c|}
\hline $\begin{array}{c}\text { Umur } \\
\text { (tahun) }\end{array}$ & (orang) & $\begin{array}{c}\text { Jumlah } \\
\%\end{array}$ \\
\hline $16-20$ & 7 & 19 \\
\hline $21-30$ & 28 & 78 \\
\hline $31-37$ & 1 & 3 \\
\hline Jumlah & 36 & 100 \\
\hline
\end{tabular}

Tabel 6. Lama Penggunaan Smartphone Unpatti

\begin{tabular}{|c|c|c|}
\hline $\begin{array}{c}\text { Lama Penggunaan } \\
\text { Smartphone }\end{array}$ & (orang) & $\begin{array}{c}\text { Jumlah } \\
\%\end{array}$ \\
\hline$<1$ Tahun & 3 & 6 \\
\hline$>3$ Tahun & 47 & 94 \\
\hline Jumlah & 50 & 100 \\
\hline
\end{tabular}

Tabel 7. Lama Penggunaan Smartphone UKIM

\begin{tabular}{|c|c|c|}
\hline $\begin{array}{c}\text { Lama Penggunaan } \\
\text { Smartphone }\end{array}$ & (orang) & $\begin{array}{c}\text { Jumlah } \\
\%\end{array}$ \\
\hline$<1$ Tahun & 3 & 8 \\
\hline$>3$ Tahun & 33 & 92 \\
\hline Jumlah & 36 & 100 \\
\hline
\end{tabular}

Tabel 8. Ukuran Layar Smartphone UNPATTI

\begin{tabular}{|c|c|c|}
\hline $\begin{array}{c}\text { Lama Penggunaan } \\
\text { Smartphone }\end{array}$ & (orang) & $\begin{array}{c}\text { Jumlah } \\
\%\end{array}$ \\
\hline $4-4,5 "$ & 9 & 18 \\
\hline $4,7-5,2 "$ & 27 & 54 \\
\hline $5,5-6,5 "$ & 14 & 28 \\
\hline Jumlah & 50 & 100 \\
\hline
\end{tabular}


Tabel 9. Ukuran Layar Smartphone UKIM

\begin{tabular}{|c|c|c|}
\hline $\begin{array}{c}\text { Lama Penggunaan } \\
\text { Smartphone }\end{array}$ & (orang) & $\begin{array}{c}\text { Jumlah } \\
\%\end{array}$ \\
\hline $4-4,5 "$ & 5 & 14 \\
\hline $4,7-5,2 "$ & 18 & 50 \\
\hline $5,5-6,5 "$ & 13 & 36 \\
\hline Jumlah & 36 & 100 \\
\hline
\end{tabular}

Tabel 10. Kegiatan yang sering dilakukan pada Smartphone UNPATTI

\begin{tabular}{|c|c|c|}
\hline $\begin{array}{c}\text { Lama Penggunaan } \\
\text { Smartphone }\end{array}$ & (orang) & $\begin{array}{c}\text { Jumlah } \\
\%\end{array}$ \\
\hline Game & 5 & 0,1 \\
\hline Internet & 16 & 32 \\
\hline Media Sosial & 28 & 56 \\
\hline Lainnya & 1 & 2 \\
\hline Jumlah & 50 & 100 \\
\hline
\end{tabular}

Tabel 11. Kegiatan yang sering dilakukan pada Smartphone UKIM

\begin{tabular}{|c|c|c|}
\hline $\begin{array}{c}\text { Lama Penggunaan } \\
\text { Smartphone }\end{array}$ & (orang) & $\begin{array}{c}\text { Jumlah } \\
\%\end{array}$ \\
\hline Game & 8 & 0,22 \\
\hline Internet & 11 & 31 \\
\hline Media Sosial & 17 & 47 \\
\hline Lainnya & 0 & 0 \\
\hline Jumlah & 36 & 100 \\
\hline
\end{tabular}

\section{Hasil uji validitas dan reabilitas}

Dari keseluruhan kuisioner yang di dapat dilakukan uji validitas dan reabilitas. Dari hasil uji validitas terhadap 86 kuisioner menunjukan hasil data yang valid $100 \%$ dan uji reabilitas dengan nilai alpha crobach's $=0,960$. Hal ini menunjukan bahwa data yang di dapat telah reliabel.

\section{Hail Evaluasi Heuristic secara keseluruhan}

Dari hasil perhitungan data yang telah dilakukan di dapat bahwa nilai rata-rata severity rating secara keseluruhan yaitu 3.08. Hasil ini menunjukan bahwa evaluasi user interface dari aplikasi gojek secara keseluruhan yaitu “ Cosmetic Problem. Selain itu juga kami juga mengevaluasi per bagian dari aplikasi gojek. Untuk hasilnya bias dilahat seperti gambar di bawah ini :

\section{SEVERITY RATING}

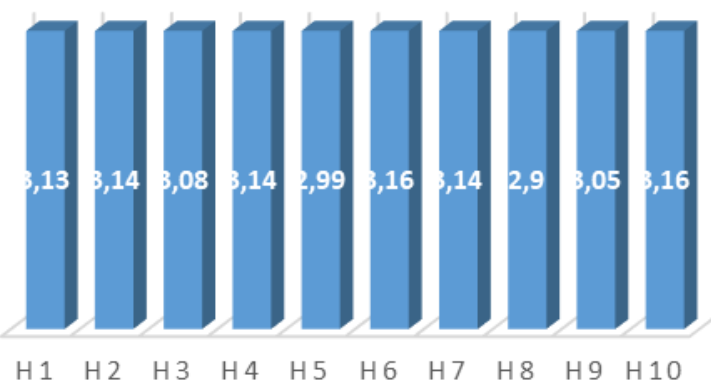

Gambar 2. Severity Rating Per Bagian Aplikasi Gojek

Dari gambar 2, menunjukan data 8 bagian yang memiliki severity rating 'Cosmetic Problem' yaitu $\mathrm{H} 1$, H2,H3,H4, H6, H7, H9, H10. Sedangkan 2 lainya memiliki nilai ' minor Problems'.

\section{Evaluasi Kekurangan dari Aplikasi Gojek}

Selain mengevaluasi keseluruhan system, kami juga melakukan evaluasi maslah per bagian. Daftar masalah pada system Gojek Aplikasi dapat dilihat seperti tabel 12, di bawah ini :

Tabel 12. Masalah - masalah severity rating pada Gojek

\begin{tabular}{|c|c|l|c|}
\hline H & Kuisioner & \multicolumn{1}{|c|}{ Penjelasan } & $\begin{array}{c}\text { Severity } \\
\text { Rating }\end{array}$ \\
\hline H3 & C3 & Pengguna Kesulitan dalam memulai dan menghentikan tugas sendiri & 2.99 \\
\hline H5 & E1 & Pengguna masih mengalami kesulitan dalam memahami error handling & 2,99 \\
\hline H8 & H2 & $\begin{array}{l}\text { Pengguna masih banyak belum memahami singkatan-singkatan dari go- } \\
\text { jek }\end{array}$ & 2.56 \\
\hline H8 & H4 & Informasi yng diberikan kepada penguna naya sebagian kecil & 2.74 \\
\hline H9 & I1 & $\begin{array}{l}\text { Pengguna masih mengalami kesulitan untuk mengetahui kesalahan dan } \\
\text { memperbaiki pada sistem }\end{array}$ & 2,97 \\
\hline
\end{tabular}


Dari hasil tersebut menunjukan bahwa aplikasi Gojek memiliki kelemahan pada H3 (1 problem), H5 (1 Problem), H8 (2 problem) dan H9 (1 Problem). Hal ini menunjukan bahwa masih ada beberapa problem yang masih harus diperbaiki.

\section{Pembahasan :}

Dari hasil data yang telah di evaluasi secara keseluruhan menunjukan bahwa aplikasi gojek memiliki kelemahan pada H5 yaitu "Error Prevention" . hal ini menunjukan bahwa pada user interface gojek masih memiliki kelemahan dalam opsi konfimasi kepada pengguna sehingga dapat menyebabkan kesalahan-kesalahn pada pengguna dalam melakukan interaksi pada aplikasi.

Hal ini juga ditunjukan dengan ditemukan masalah pada H5 yaitu pennguna masih kesulitan dalam melakukan error handling, hal ini membuktikan bahwa system error handling pada aplikasi gojek terutama pada user masih memiliki kelemahan.

Hasil evaluasi yang lainnya di dapat menunjukan bahawa terdapat kelemahan pada H8 "Aestetich and Minimalist design. Hal ini menunjukan bahwa sering terjadinya pemberian informasi yang yang tidak relevan dan dibutuhkan oleh penngguna, sehingga setiap informasi tambahan yang mesuk mengurangi visibility dari informasi yang relative.

Hasil evaluasi H8 ini juga dibuktikan dengan 2 hasil kelemahan yang di dapat yaitu masih banyaknya pengguna yang masih belum memahami singkatansingkatan informasi dari gojek serta masih sedikitnya informasi yang diberikan gojek kepada pengguna. Sehingga menyebabkanpengguna gojek kesulitan dalam memahami informasi yang dibutuhkan pengguna di aplikasi gojek.

Hasil evaluasi selanjutnya menunjukan bahwa H9 memiliki masalah yaitu pengguna masih mengalami kesulitan dalam mengetahui kesalahan dan meperbaikinya. Hal ini menunjukan bahwa pesan kesalahan yang ada pada aplikasi gojek masih memiliki kelemahan dikarenakan informasi yang diberikan masih belum informatif dan solutif.

Dari hasil evaluasi problem secara rinci didapat bahwa aplikasi gojek memiliki kelemahan bagi pengguna dalam melakukan pemulaian dan penghentian penggunaan aplikasi. Hal ini menunjukan bahawa system user control and freedom pada aplikasi gojek masih memiliki kelemahan.

\section{KESIMPULAN}

Sistem error handling pada aplikasi gojek masih memiliki masalah sehingga perlu perbaikan pada saat pengembangan pada aplikasi gojek dalam system error handling agar memudahkan pengguna dalam menerima konfirmasi dari gojek.

Pada aplikasi gojek diperlukan pebaikan pada bagian Estetika dan desain terutama singgkatan singkatan informasi serta informasi yang dibutuhkan pengguna, sehingga dengan adanya pemahanan singkatan pada pengguna dapat memudahkan pengguna dalam mendapatkan informasi yang akurat.

Pada aplikasi gojek perlu perbaikan dalam penyelesaian masalah pada system pengguna. Sehingga pengguna dapat dengan sendirinya mengatasi masalah dengan sendirinya jika terjadi kesalahan pada system saat sedang digunakan.

Pada penelitian ini ditemukan tiga masalah utama yaitu, system error, estetika dan desain serta pesan kesalahan. Sehingga dalam penilitian selanjutnya peneliti menyarankan untuk melakukan penelitian pada tiga masalah tersebut dalam penelitan selanjutnya.

\section{UCAPAN TERIMA KASIH}

Ucapan terima kasih, kami sampaikan kepada pihak Direktorat Riset \& Pengabdian Masyarakat Kementerian Riset, Teknologi \& Pendidikan Tinggi yang telah mendanai penelitian ini dan kepada pihak Universitas Kristen Indonesia Maluku (UKIM) yang telah memberikan dukungan sehingga penelitian ini dapat terlaksana dengan baik.

\section{DAFTAR PUSTAKA}

[1] I. Akuntono, "Datang ke Istana, Pendiri GoJek Beri Masukan untuk Pemerintah," Kompas, 2015.

[2] F. D. Amajida, "Kreativitas Digital Dalam Masyarakat Risiko Perkotaan: Studi Tentang Ojek Online ‘Go-Jek’ Di Jakarta,” Informasi, vol. 46, no. 1, p. 115, 2016, doi: 10.21831/ informasi.v46i1.9657.

[3] A. Azizah and P. R. Adawia, "Analisis 
Perkembangan Industri Transportasi Online di Era Inovasi Disruptif (Studi Kasus PT Gojek Indonesia)," Cakrawala - J. Hum., vol. 18, no. 2, pp. 149-156, 2018, doi: 10.31294/JC.V18I2.4117.

[4] M. Desrianto, "Nadiem Makarim: Gojek Majukan UMKM di Indonesia," Kompas, Apr. 2019.

[5] A. H. Pratam, "Kilas Balik Perkembangan Ojek Online di Indonesia Sepanjang tahun 2015," techinasia.com, 2015.

[6] J. Nielsen, "Usability 101: Introduction to Usability," Nielsen Norman Group, All Rights Reserved, 2012. https://www.nngroup.com/ articles/usability-101-introduction-tousability/.

[7] K. R. Hadi, H. M. Az-zahra, and L. Fanani, "Analisis Dan Perbaikan Usability Aplikasi Mobile KAI Access Dengan Metode Usability Testing Dan Use Questionnaire," J. Pengemb. Teknol. Inf. dan IImu Komput., vol. 2, no. 9, pp. 2742-2750, 2018.

[8] A. Fernandez, E. Insfran, and S. Abrahão, "Usability evaluation methods for the web: A systematic mapping study," Inf. Softw. Technol., vol. 53, no. 8, pp. 789-817, 2011, doi: 10.1016/j.infsof.2011.02.007.

[9] J. Marenkov, T. Robal, and A. Kalja, “DesignTime Web Usability Evaluation with Guideliner," Complex Syst. Informatics Model. Q., no. 15, pp. 90-109, 2018, doi: 10.7250/csimq.2018-15.05.
[10] F. N. Muhammad and A. D. Herlambang, “Evaluasi Desain Antarmuka Aplikasi Mobile BPJS Ketenagakerjaan Menggunakan Heuristic Evaluation," J. Pengemb. Teknol. Inf. dan IImu Komput. Univ. Brawijaya, vol. 2, no. 1, pp. 433-440, 2018.

[11] J. Nielsen, Usability Inspection Methods. Nielsen Norman Group, All Rights Reserved, 1994.

[12] U. Ependi, "Heuristic Evaluation for Mobile Application (Studi Kasus: Aplikasi Depo Auto 2000 Tanjung Api Api Palembang)," Simetris J. Tek. Mesin, Elektro dan IImu Komput., vol. 8, no. 2, p. 563, 2017, doi: 10.24176/ simet.v8i2.1525.

[13] D. Caesaron, "Evaluasi Heuristic Desain Antar Muka (Interface) Portal Mahasiswa (Studi Kasus Portal Mahasiswa Universitas X)," J. Metris, vol. 16, pp. 9-14, 2015.

[14] R. H. Y. Fung, D. K. W. Chiu, E. H. T. Ko, and K. K. W. Ho, "Heuristic Usability Evaluation of University of Hong Kong Libraries' Mobile Website," J. Acad. Librariansh., vol. 42, no. 5, pp. 581-589, 2016, doi: 10.1016/ j.acalib.2016.06.004.

[15] G. Norman, "Likert scales, levels of measurement adn the 'laws' of statistics," Adv. Heal. Sci. Educ., vol. 15, no. 5, pp. 625 -632, 2010, doi: 10.1007/s10459-0109222-y. 
$\begin{array}{lll}\text { Majalah IImiah UNIKOM } & \text { Vol.18 No. } 2\end{array}$

\begin{tabular}{l|l} 
Hal a man & $\mathbf{7 2}$
\end{tabular} 